Ting-Yu Lee

(Uniwersytet Warszawski)

\title{
A Cross-Cultural Study of Collectivism and Individualism at Workplace: A Case Study of Taiwanese Managers versus Polish Employees
}

\section{Introduction}

Cross-cultural studies have constantly attracted social scientists' attention in recent decades due to the comprehensive need for understanding the characteristics of and differences between various cultures and social groups. The world today no longer consists of nations where people can live and survive alone by themselves, but nations must establish either a certain level of economic or political connection with other nations. The existence of international organizations, such as the European Union (EU) and the United Nations (UN), serve as the best examples of international cooperation and integration in terms of politics and the economy. Hence, understanding the various meanings embedded in different cultures becomes an important issue for many enterprises and organizations when they intend to conduct political and commercial activities in a foreign country. However, it cannot be ignored that every person carries his/her patterns of thinking, feeling and potential acting, which are learned throughout their lifetime. Much of it has been acquired in early childhood, because at that time a person is most susceptible to learning and assimilating. As soon as certain patterns of thinking, feeling and acting have been established in themselves within a person's mind, she/he must unlearn these before being able to learn something different, and unlearning is more difficult than learning for the first time (Hofstede 1991).

Cross-cultural studies have continuously increased in all the social sciences; however, they usually lack a theory of the key variable "culture" itself. Hofstede was the pioneer who conducted a cross-cultural study on examining the different cultural values lying in four dimensions of national cultures (i.e. power distance, uncertainty avoidance, individualism and masculinity) over forty countries from 1968 until 1974. It has been argued by Hofstede (1980) that "people carry mental programs which are developed in their families in early childhood and reinforced in school, organizations, and that these mental programs contain 
a component of national culture" (p. 11). In terms of the four dimensions of national cultures proposed by Hofstede (1980), why is it so important to study collectivism and individualism in post-communist societies, especially in Poland? There are three main reasons: (1) the limited number of empirical studies on individualism and collectivism in post-communist countries; (2) Europe today: the enlargement of the European Union (EU) versus cross-cultural management; and (3) the influence of culture on multinational enterprises versus the mental transition in post-communist society in Poland, i.e. are Poles individualists or collectivists? Hence, the main purpose of current study is aimed (a) to understand the inter-correlation between the mental adjustments to the postcommunist system in terms of personality characteristics acquired from families and the shifting tendencies from collectivism to individualism in work values during the post-communist transitional period in Poland; (b) to explore the influence of cultural differences on multinational business, i.e. what is important for a (foreign) manager to know when entering the Polish market in a transitional society.

\section{Theoretical Background of Individulism vs. Collectivism and Hypotheses}

Hofstede (1991) assumes "cultures as mental programming" (p. 4). Almost everyone belongs to a number of different groups and categories of people at the same time, and people unavoidably carry several layers of mental programming within themselves. As Hofstede (1991) divides national culture into several layers, this sort of mental programming corresponds to the following levels of culture: (1) national, according to one's country; (2) regional, ethnic, religious, or linguistic affiliation; (3) gender; (4) generation; (5) social class; and (6) for those who are employed, an organizational or corporate one (p. 10). In modern society, the mental programs from these various levels of cultures are not necessarily in harmony in different countries. Hence, cultures differ from country to country. A certain background provides people with different values, a certain culture, and a certain collective programming in their mind (Hofstede 1991). Consequently, various social groups or societies reveal different traits and attitudes in their behavior. Nations remain as sources of the common mental programming for their citizens.

Furthermore, Hofstede (1991) suggests that "understanding the differences in the ways these leaders and their followers think, feel, and act is a condition for bringing about worldwide solutions that work" (p. 4). It is concluded by Hofstede that although the variety in people's minds is enormous, there is a structure in this variety which can serve as a basis for mutual understanding. For this reason, a cultural study regarding people's mental programming is an essential instrument for understanding national cultures. 
The origins of the study of individualism and collectivism are from Hofstede's IBM study. Hofstede (1976) conducted a study on cross-cultural differences in the international company IBM. Through his research he discovered that respondents from different countries are characterized by different beliefs and values which are learned in the family. Hofstede makes a distinction between individualism and collectivism in terms of respondents' performance in the family as follows:

Individualism pertains to societies in which the ties between individuals are loose. Collectivism as its opposite pertains to societies in which people from birth onward are integrated into strong, cohesive ingroups, which throughout people's lifetime continue to protect them in exchange for unquestioning loyal (p. 51).

Hofstede's IBM analysis reports that respondents from Anglo-Saxon and West European countries tend to be individualists, and their individual index (IDV) is significantly higher than respondents from East Asian countries. Hence, he categorized respondents from different countries into collectivists and individualists. The IDV index is shown as follows in Table 1 and Table 2:

Table 1. IDV Index of Individualist Countries

\begin{tabular}{|c|c|c|}
\hline Score Rank & Country & IDV score \\
\hline 1 & USA & 91 \\
\hline 2 & Australia & 90 \\
\hline 3 & Great Britain & 89 \\
\hline $4 / 5$ & Canada & 80 \\
\hline $4 / 5$ & Netherlands & 80 \\
\hline 6 & New Zealand & 79 \\
\hline 7 & Italy & 76 \\
\hline 8 & Belgium & 75 \\
\hline 9 & Demark & 74 \\
\hline $10 / 11$ & Sweden & 71 \\
\hline $10 / 11$ & France & 71 \\
\hline
\end{tabular}

S o u r c e : Hofstede (1991: 53).

Table 2. IDV Index of Collectivist Countries

\begin{tabular}{|c|c|c|}
\hline Score Rank & Country & IDV score \\
\hline 37 & Hong Kong & 25 \\
\hline $39 / 41$ & Singapore & 20 \\
\hline 43 & South Korea & 18 \\
\hline 44 & Taiwan & 17 \\
\hline
\end{tabular}

S o u r c e : Hofstede (1991: 53). 
Moreover, according to the results above, Hofstede assumes that the roots of individualism could be found in people's families. Hofstede concludes that "in individualist cultures parents will be proud if children at an early age take small jobs in order to earn pocket-money of their own, which they alone can decide how to spend" (p. 58). On the contrary, in a collectivist society obligations to the family are not only financial but also ritual. Family celebrations like baptisms, marriages and especially funerals are extremely significant and all family members should attend. Moreover, in an individualist culture, family members or friends feel a need to communicate verbally when they meet. Silence is considered abnormal and impolite. Social conversations sometimes can be depressingly banal, but they are compulsory and essential. On the other hand, in a collectivist culture the fact of being together is emotionally sufficient; there is no compulsion to talk unless there is some information to be transferred. Hence, individualists and collectivists serve as the counterpart in many ways of social activities. It should be noted that Hofstede's study did not include postcommunist Europe. The main reason is that post-communist Europe did not exist at that time (1976) when he conducted the IBM study. Due to the enlargement of the EU and globalization, numerous managers of enterprises from Western Europe have come to the East and have started to establish their business network here. However, they do not have ample information and understanding about the region. Indeed, there is still a need for an empirical study on individualism and collectivism in post-communist society. For this reason, the present thesis aims to study individualism and collectivism at workplaces by using Poland as a case study.

Hofstede (1991) summarized the differences between collectivist and individualist societies at the workplace based on the data obtained from the IBM study. The key differences are illustrated in Table 3 as follows:

Table 3. Key Difference Between Collectivist and Individualist Societies at Workplaces

\begin{tabular}{|l|l|}
\hline \multicolumn{1}{|c|}{ Collectivist } & \multicolumn{1}{c|}{ Individualist } \\
\hline $\begin{array}{l}\text { Relationship employer-employee is perceived } \\
\text { in moral terms, like a family link. }\end{array}$ & $\begin{array}{l}\text { Relationship employer-employee is a contract } \\
\text { supposed to be based on mutual advantage }\end{array}$ \\
\hline $\begin{array}{l}\text { Hiring and promotion decision take employ- } \\
\text { ees' ingroup into account }\end{array}$ & $\begin{array}{l}\text { Hiring and promotion decisions are supposed } \\
\text { to be based on skills and rules only }\end{array}$ \\
\hline Management is the management ofgroups & $\begin{array}{l}\text { Management is the management of individu- } \\
\text { als }\end{array}$ \\
\hline Relationship prevails over task & Task prevails over relationship \\
\hline
\end{tabular}

Source: Hofstede (1991: 67).

Based on this table, Hofstede (1991) constructed the definition of individualism and collectivism as follows: 
Collectivism is the opposite of individualism; together, they form one of the dimensions of national cultures. Collectivism stands for a society in which people from birth onwards are integrated into strong, cohesive ingroups, which throughout people's lifetime continue to protect them in exchange for unquestioning loyalty. Individualism is the opposite of collectivism... Individualism stands for a society in which the ties between individuals are loose: everyone is expected to look after himself or herself and his or her immediate family only (p. 68).

The definitions of collectivism and individualism constructed by Hofstede are employed as the core ones for the discussion throughout this article.

\subsection{Hypotheses}

Two recent studies are closely related to the measurement of individualism and collectivism in post-communist Europe, especially in Poland. The first one is Work Values Shift Tendencies under the Post-Communist Transition Period conducted by Stamenova (1999). He suggests that during the post-communist period, there have been some difficulties and possibilities that have to be overcome in order to develop a post-modern work orientation in Poland and Bulgarian. Another related study was conducted by Ging (1999) - Freedom as a Value in Transitional Poland. She concludes that political reform results in the demand of freedom from the workplaces from Poles. In transitional Poland, Poles have started to think about the freedom they should have from the authority in the workplaces. Consequently, Poles' mental programming has been gradually changing during the transitional period in Poland. These results could be used to explain the change of the national culture and then could be applied to intercultural management in Poland. In addition, Slomczynski (1999) suggests that the years 1989-1991 could be regarded as the transitional period in Polish society after the fall of Communism. The year 1992 to the present could be considered as the post-communist period. Hence, in the present thesis, the first hypothesis is proposed in order to understand the process and transition of individualism and collectivism in a particular post-communist country, i.e. Poland, as follows:

Hypothesis One: Polish employees tend to be more individualistic regarding work goals during the post-communist period than during the transitional period at workplaces.

Moreover, Tomasz Mroczkowski (1999) claims that "recent economic reforms in Poland have created very different approaches to organizing business and social institutions" (p. 6). Hofstede (1983) suggests that the Polish business environment is converging to Western practice. For this reason, he assumes that economic progress brings with a shift values from collectivism to individualism. Hence, the second hypothesis is proposed to explore the consequence of the shifting work values between collectivism and individualism and the convergence to Western work values in Poland as follows: 
Hypothesis Two: The shifting tendencies of work values from collectivism to individualism at workplaces in Poland leads to a convergence with West European work values.

Mroczkowski (1999) conducted a study on the management between old and young Poles. He discovers that

Polish young people may now hold values less oriented towards the collectivism of a Communistsociety, may practice less rigid ways of thinking than that preached by Communist dogma, and now they may find meaning in their work through achievement and self actualization (p.6)

Mroczkowski's finding suggests that age difference may influence the work attitude among Poles. For this reason, the third hypothesis was constructed to examine the consequence between the factor of age difference and the collectivism of a Communist society.

Hypothesis Three: Age difference among Polish employees at workplaces results in a different attitude towards collectivism of a Communist society.

Hofstede (1991) confirms that long-tern orientation is one of the key factors and results in economic growth in East and East South-Asian countries (Japan, Taiwan, Singapore, South Korea and Hong Kong). The consequence of Confucian dynamism and economic growth has already been discussed in Section 1.5. Hofstede (1991) also confirms that people from East-Asian countries tend to have a higher level of long-term orientation than people from other regions (see Table 5). In Table 5, the ranking of Poland is 13 among 23 countries. This result may raise a question as to how East-Asian managers will supervise and manage Polish employees. For this reason, the forth hypothesis is proposed to provide a realistic picture of the relationship between East Asian managers and Polish employees.

Hypothesis Four: Compared to employees from Taiwan, Polish employees tend to ignore the long-term orientation at workplaces.

\section{Rejection/Confirmation of Hypotheses}

Hofstede's statistical analysis of the degree of individualism is based on the work goals. He asserts that the work goal in regard to individualism contains personal time, freedom and challenge. As it was previously mentioned, according to Slomczynski's analysis, the years 1989-1991 could be regarded as the transitional period in Polish society after the fall of Communism, from year 1992 to the present could be considered as the post-communist period. Hence, the data obtained from European Value Survey 1990-1991 and 1999-2002 is employed to compare the shifting tendency of individualism in Poland. The statistical date of degree of individualism among Poles is from the data obtained from European Value Survey 1990-1991 and 1999-2002. The questions related to work 
goals of individualism, such as the importance of personal time, freedom, initiative and achievement, are selected as the independent variables from European Value Survey. Hofstede (1991) suggested that the importance of personal time, freedom, initiative and achievement are the construction of individualism related to work goals. European Value Survey participants are requested to choose from the two options - mentioned and not mentioned of each research question. The option of mentioned means that the respondents agree to the research question, while not mentioned means the respondents do not agree. The percentage of the degree of individualism among Poles is from the amount of Poles who chose the option of mentioned divided the whole Polish sample population. The same statistical method is applied to the percentages of the other seven Western European countries. The formulas are as follows:

The degree of individualism related work goals $=$ the importance of personal time + the importance of freedom + the importance of initiative + the importance of achievement

The percentage of the importance of personal time $=$ the amount of subjects who chose mentioned answer (i.e. personal time of work is important to me) / the whole sample population of each country

It is shown in Chart 1 that the degree of individualism related to work goals, such as freedom, initiative and achievement increase significantly in the postcommunist period (1999-2002) than those in the transitional period (19901991). The importance of freedom increased 16 percent ( $47 \%$ to $63 \%)$, initiative 11 percent (38\% to $49 \%$ ) and achievement 18 percent (48\% to 66\%), respectively. Personal time regarding to work goals is the only exception. Compared to the transitional period (1990-1991), it slightly decreased 3\% (53\% to 50\%). For this reason, the first hypothesis is confirmed by the statistical analysis that Polish employees tend to be more individualistic regarding work goals during the postcommunist period than during the transitional period at workplaces.

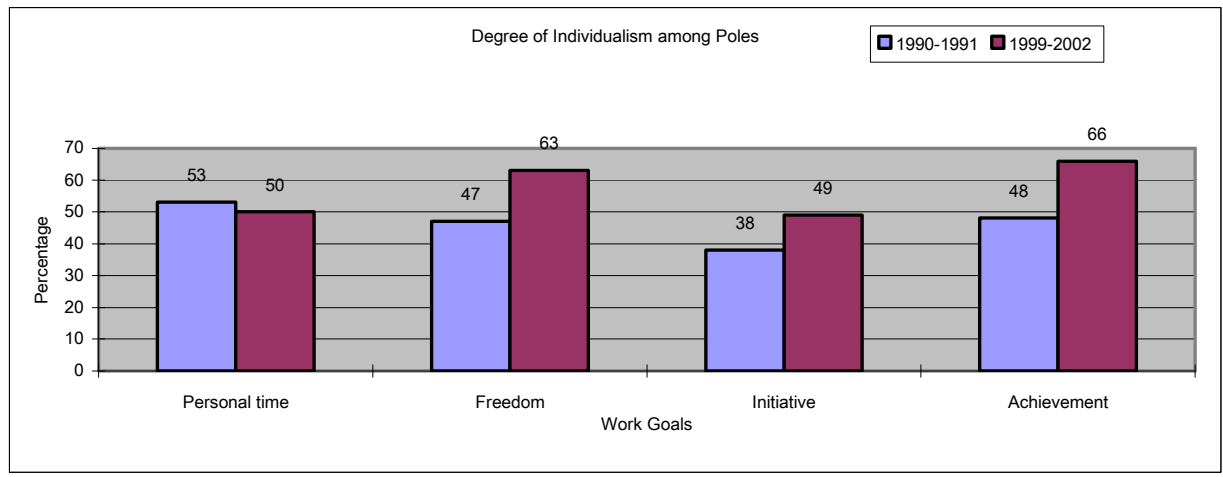

Chart 1. Degree of Individualism among Poles 
The second hypothesis is also tested by the same group of values related to work goals, including the importance of personal time, freedom, initiative and achievement. This group of work values is employed to compare the shifting work value among Poles with other seven individualist countries (France, Britain, Italy, Netherlands, Belgium, Denmark and Sweden) during the post-communist period (the years 1992 to the present).

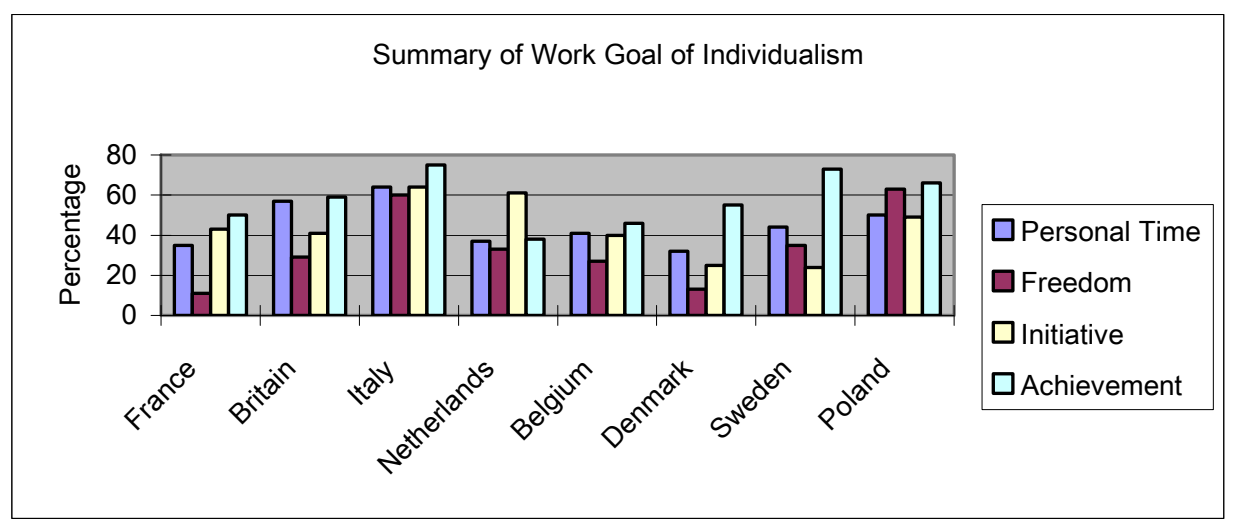

Chart 2. Summary of Work Goals Related to Individualism: Poland and Individualist Countries

As the data in Chart 2 shows, Poland and other seven European countries more or less converge at the importance of personal time, initiative and achievement in regard to work goals, except for the importance of freedom.

Hofstede (1991) indicates that the work goals including personal time, freedom, initiative and achievement are directly linked to the degree of individualism. For this reason, along with the confirmation of the first hypothesis, the second hypothesis is confirmed that the shifting tendencies of work values from collectivism to individualism at workplaces in Poland leads to a convergence with West European work values.

The third and forth hypotheses will be examined by data obtained from the second open-ended question in Part Three of the Individualist versus Collectivist at Workplaces questionnaire that I designed. The Taiwanese managers were asked the following question "In your opinion, does age difference among Polish employees/colleagues make their work attitudes distinctive from each other? For example, younger Poles tend to work individually and care about their work achievement. On the other hand, older Poles tend to work collectively. Yes or No? Why?". Regarding their answers, there was only one Taiwanese manager who considers that there is a difference between younger and older Polish employees. For example, he stated that "there is much difference between them, the employees from communist time are more conservative and narrow-minded; they do not emphasize work performance, but enjoy having vacation and reward 
from the boss." The remaining five managers consider that there is little or no difference between younger and older Polish workers. For instance, one respondent said that there is "no difference. No matter [if they are] young or old employees, they nearly have the same nature working type: lazy and dishonest." Another respondent claimed that "there is not much difference between them. The employees from communist time are more conservative and narrow-minded. They do not emphasize work performance, but enjoy having vacation and reward from the boss." And another manager said that there is "no difference. It depends on their character." Hence, the third hypothesis is rejected that from Taiwanese managers' points of view: the age difference among Polish employees at workplaces does not result in a different attitude towards collectivism of a Communist society. The fourth hypothesis is tested by the results of the third research question. The managers were asked the following: "Compared to Taiwanese employees, do Polish employees tend to ignore the long-term orientation at their workplaces? If so, why?" According to the answers obtained from the managers, they all agree to that compared to employees from Taiwan, Polish employees tend to ignore long-term orientation at workplaces. Two Taiwanese managers indicated that their Polish employees do not respect their authority. They describe them as follows: "Polish employees tend to be selfdefensive for their work performance no matter [if] their boss does not agree with their opinion; compared to Polish employees, Taiwanese employees tend to agree to the opinion of their boss or supervisor first in order to keep their "face."" Another respondent said that "Polish employees usually are not willing to subordinate oneself for a purpose; they tend to hold their negative opinion when they discuss the event with their boss." Moreover, two of the Taiwanese managers think that his Polish employees do not care about the preparation and discussion before the meeting - "Polish employees do not care about planning or preparation before business meeting." Another manager mentioned that "compared to Taiwanese employees, Polish employees more or less are not used to the long discussion and preparation before the important business meeting with new customers." Therefore, the fourth hypothesis is confirmed by the answers of Taiwanese managers that compared to Taiwanese employees, Polish employees tend to ignore long-term orientation at workplaces.

\section{Conclusion}

The fall the communist regime in Poland led to the dramatic transformation of people's mental programming from the collectivism of communism to the individualism of Western values at workplaces. In the communist era, people's civil rights and freedom were confined to collective behaviours. Citizens during the communist era were not allowed to voice their own opinion and manifest 
their work achievement; they were taught to work collectively for the group's interests, rather than their own interests. After the collapse of the communism in 1989, Poles regained their civil rights and freedom in the new democratic system. They are allowed to travel abroad, participate in political activities and voice their opinion to the government. As a result, Poles begin to act and work individually at the workplaces. It is confirmed by the exploration of the first hypothesis of the present thesis that Poles tend to be more individualistic at workplaces during the post-communist period than in the transitional period. The change of political system serves as the agent to prompt the emergence of individualism at workplaces as well. The shifting tendency from the collectivism of communism to individualism leading to a convergence with Western work values is proven by the second hypothesis of the present thesis.

In addition, after the change of political system in 1989, the Polish capitalist market opened its door to Western and Asian investors. An increasing numbers of international enterprises from other cultural backgrounds conducted their businesses and set up their branch offices in Poland. Indeed, the cultural barrier exists between Polish employees and foreigner managers (Hofstede 1999 and Makulaviciene 1999). However, there are a limited number of cross-cultural studies related to the management between East-Asian managers and Polish employees. As a result, the third and forth hypotheses in the present thesis were constructed explore the cultural differences, such as age difference related to work attitude and long-term orientation towards work responsibilities, embedded in the cross-cultural management between Taiwanese managers and Polish employees. From Taiwanese mangers' points of view, age difference does not result in the different work values among Poles. Poles' work attitude is dependent on their own personality. They conceive that compared to Taiwanese employees, Polish employees ignore the long-term orientation at workplaces. Taiwanese managers consider that Poles usually tend to be self-defensive towards their own opinions related to their duties, which is a rare phenomenon in East-Asian management. This wide cultural gap between East-Asian managers and Polish employees results in the miscommunication and misunderstanding at the workplaces. Although the miscommunication and misunderstanding of cultural differences do not bring great frustration for Taiwanese managers, there are still some efforts that could be made for the improvement of binary communication between the both sides. Hence, it is suggested from the results of this thesis that more studies should be conducted on management between EastAsian managers and Polish employees at workplaces in order to understand the level of cultural differences embedded in the miscommunication and metacognition on cultural differences between East-Asian managers and Polish employees.

In conclusion, now that Poland has joined the EU more and more significant cooperation between West European countries and Poland is continuously taking 
place either officially in the pubic institutions or privately in social organizations. The shifting tendency of work values from the collectivism of the communism to the convergence of the individualism of West work values could be seen as the positive consequence after the change of the political system for the international cooperation between Poland and West European countries. After the transitional period, Poles tend to act more independently and pursue their achievement from the work goals in order to improve quality of their everyday life and economic interests. This tendency of becoming individualists could be considered as the agent to encourage Poles to attain the national wealth of West European countries.

\section{References}

\section{Books}

Bauman, Zygmunt (1990). Think Sociologically. Cambridge: Blackwell Publishers. Hofstede, Geert (1980). Culture's Consequences. New York: Sage Publications. Hofstede, Geert (1991). Cultures and Organization. New York: McGraw-Hill. Holmes, Leslie (1997). Post-communism an Introduction. Cambridge: Blackwell Publishers.

Roderick Martin, (1999). Transforming Management in Central and Eastern Europe. Oxford: Oxford University Press.

Slomczynski M. Kazimierz et al. (1999). Mental Adjustment to the Post-Communist System in Poland. Warsaw: IFiS Publishers.

\section{Articles}

Belka, Marek (2001). "Lessons from Polish Transition", in George Blazyca and Ryszard Rapacki (ed.), Poland into the New Millennium, Edward Elgar Publishing, p. 13-32.

Boone, Christophe (2004). "Individualism and Collectivism: Cross-national Differences in the Impact of Culture on Labor Market Outcome", Paper for the RC 28 Meeting in Neacktel.

Cairns, Ed. et al. (2004). "Social Capital, Collectivism-Individualism and Community Background in Northern Ireland", A Report to the Office of the First Minister and the Deputy First Minister and the Head of the Voluntary and Community Unit of the Development for Social Development.

Giang, Nguen Thanh (1999). "Freedom as a Value in Transitional Poland", in Jadwiga Koralewicz (ed.), The European Value System, PAN ISP and Collegium Civitas Press, p. 88-115.

Hey, Le et al. (1999). "Collectivism-Individualism and Cooperation: A Cross-Cultural and CrossLevel Examination". Michigan: University of Michigen Press.

Inglehard, Ronald and Oyserman Daphna (1999). "Individualism, Autonomy and Self-Expression: The Human Development Syndrome". Michigen: University of Michigan Press.

Kerr, Roger (1997). "What's All This about Individualism". Aucklland: New Zealand Business Roundtable Publisher.

Makulaviciene, Alge (1999). "The Influence of Cultural Differences on Multinational Business, or what is Important to Know for a Manager when Entering a New Market with an Overview of a Polish Case", in Jadwiga, Koralewicz (ed.), The European Value System, PAN ISP and Collegium Civitas Press, p. 167-191. 
McSweeney, Brendan (2002), "Hofstede's Model of National Cultural Differences and Their Consequences: A Triumph of Faith - A Failure", Published in Human Relations, Vol. 55, No. 1, January 2002, p. 89-118.

Moran, J. (2001). "Democratic Transitions and Forms of Corruption". Kluwer Academic Publishers.

Mroczkowski, Tomasz (1999). "Differing interpretation of key management terms: old versus new Poland", Research Working Paper Published by Copenhagen Business School.

Oudenaren, Van, John (1999). "EU Enlargement: The Return to Europe" in Ronald, Tiersky (ed.), Europe Today, Rowman \& Littlefield Publishers.

Pohorila, Nataliya (1999). "Structure or Culture? Cross-National Analysis of Market Values Determination in Western and Eastern Europe" in Jadwiga, Koralewicz (ed.), The European Value System, PAN ISP and Collegium Civitas Press, p. 8-45.

Rapacki, Ryszard (2001). "Economic Performance 1989-1999 and Prospects for the Future" in George Blazyca and Ryszard Rapacki (ed.), Poland into the New Millennium, Edward Rlgar Publishing, p. 107-141.

Savicka, Aida (1999). "Economic Performance and Work Ethnic: The Comparison of European Countries" in Jadwiga, Koralewicz (ed.), The European Value System, PAN ISP and Collegium Civitas Press, p. 131-166.

Schulruf, B. et al. (2003). "Development of a New Measurement Tool for Individualism and Collectivism. Paper Presented at the NZARE/AARE. Joint Conference 2003”, Aucklland, New Zealand.

Stamenova, Svetlana (1999). "Work Valuea Shift Tendencies during the Post-Communist Transformation Period - Possibilities and Difficulties in Building up Post-Modern Value Orientation - The Polish and Bulgarian Experience" in Jadwiga, Koralewicz (ed.), The European Value System, PAN ISP and Collegium Civitas Press, p. 63-86.

Tiersky, Ronald (1999). "Europe Today: The Integration-Security Link" in Ronald, Tiersky (ed.), Europe Today. Rowman \& Littlefield Publishers. 